\title{
IN-HOME CONSUMER EVALUATIONS OF INDIVIDUAL MUSCLES FROM BEEF ROUNDS SUBJECTED TO TENDERIZATION TREATMENTS
}

\author{
A Thesis \\ by \\ STACY LAYNE MUELLER \\ Submitted to the Office of Graduate Studies of \\ Texas A\&M University \\ in partial fulfillment of the requirements for the degree of \\ MASTER OF SCIENCE
}

December 2005

Major Subject: Animal Science 


\title{
IN-HOME CONSUMER EVALUATIONS OF INDIVIDUAL MUSCLES FROM BEEF ROUNDS SUBJECTED TO TENDERIZATION TREATMENTS
}

\author{
A Thesis \\ by \\ STACY LAYNE MUELLER

\begin{abstract}
Submitted to the Office of Graduate Studies of
Texas A\&M University

in partial fulfillment of the requirements for the degree of

MASTER OF SCIENCE
\end{abstract}

Approved by:

Chair of Committee, Jeffrey W. Savell

Committee Members, Daniel S. Hale

Rudolfo M. Nayga

Head of Department, Gary R. Acuff

December 2005

Major Subject: Animal Science 


\begin{abstract}
In-Home Consumer Evaluations of Muscles from Beef Rounds Subjected to Tenderization Treatments. (December 2005)

Stacy Layne Mueller, B.S., Texas A\&M University

Chair of Advisory Committee: Dr. Jeffrey W. Savell
\end{abstract}

An in-home evaluation of beef value cuts from the round was conducted to determine ways to improve palatability attributes for steaks prepared by consumers. The M. vastus lateralis, $M$. rectus femoris, $M$. semimembranosus, and $M$. adductor $(\mathrm{n}=266)$ muscles were either blade tenderized, enhanced with a salt and phosphate solution, or served as a control. Consumers $(n=261)$ cooked these steaks as they normally would and were asked to document cooking method and degree of doneness, as well as palatability ratings for overall like, tenderness, juiciness, flavor intensity, and flavor desirability for each steak. Enhancing round muscles with a salt and phosphate solution improved most palatability traits compared to those that were blade tenderized or not treated. For M. semimembranosus and M. vastus lateralis, the enhanced steaks received higher $(P<0.05)$ ratings for all palatability traits. For the most part, cooking method and degree of doneness had little influence on consumer palatability ratings. Where differences occurred, they were muscle specific, which may allow limited recommendations for certain muscles with respect to the most appropriate cooking method and degree of doneness. 


\section{DEDICATION}

I dedicate this paper to the 2005 meat judging team. Thank you for allowing me to lead you on a truly remarkable journey and dedicating yourselves, for a year and a half, to a team that will truly have an impact for a lifetime. 


\section{ACKNOWLEDGEMENTS}

This project was funded, in part, by beef and veal producers and importers through their \$1-per-head checkoff, and was produced for the Cattleman's Beef Board and state beef councils by the National Cattleman's Beef Association and the Texas Beef Council.

I thank the members serving on my thesis committee. Dr. Rudy Nayga provided great support and focus on the consumer end of the meat industry. Dr. Dan Hale provided constant positive encouragement and provided help without hesitation. Dr. Jeff Savell provided the opportunity to be a part of this outstanding department, section, and project, and has provided me with the tools I need to be successful in anything that I might embark upon in the future.

I would also like to thank Dr. Wes Osburn for his tremendous help throughout processing and during the writing process. Without his guidance and expertise, the project would not have been completed successfully. This work could not have been conducted without the hard work of all my fellow graduate students: Bridget Baird, Kyle Pfeiffer, Jason Bagley, Andy King, Carrie Adams, Celeste Schuehle, Diana Huerta, Kristin Voges, Kelton Mason, and Danielle Espitia. Also, I would like to thank all of the student workers in the department for their assistance throughout the project; Keri Bagley, LeeAnn Sitka, Katie Leigh, Earl Bates, and Katelyn Edwards. Without the caring and cooperation of the Ray Riley and the Rosenthal meat lab workers, I would not have been able to accomplish anything. 
Lastly, I thank God, my parents, family, friends, and all of those who have helped me get to this point in my life. I feel truly blessed to have loved ones who care and support me as much as my friends and family do. 


\section{TABLE OF CONTENTS}

\section{Page}

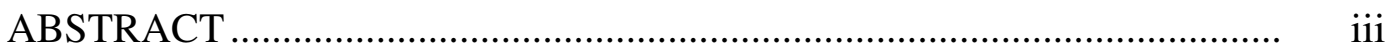

DEDICATION …....................................................................... iv

ACKNOWLEDGEMENTS ....................................................... $\mathrm{v}$

TABLE OF CONTENTS .................................................................... vii

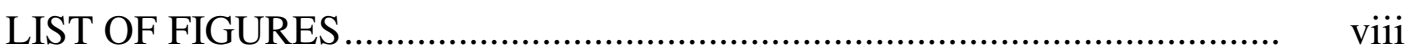

LIST OF TABLES ..................................................................... ix

CHAPTER

I INTRODUCTION AND REVIEW OF LITERATURE......... 1

II MATERIALS AND METHODS ..................................... 6

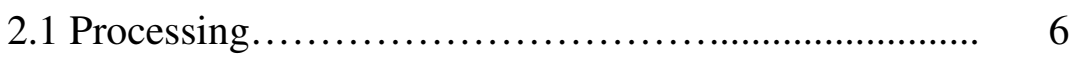

2.2 Tenderization treatments.......................... 6

2.3 Consumer recruitment .............................................. 7

2.4 Statistical analysis............................... 11

III $\quad$ RESULTS AND DISCUSSION ...................................... 12

3.1 Tenderization treatments............................. 12

3.2 Cooking method ........................................... 14

3.3 Degree of doneness...................................... 16

IV SUMMARY AND CONCLUSIONS................................. 25

REFERENCES............................................................................ 26

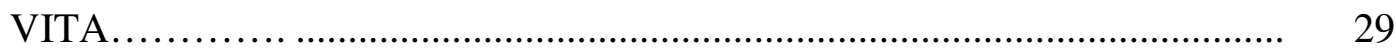




\section{LIST OF FIGURES}

$\begin{array}{ll}\text { FIGURE Page } & \text { PI }\end{array}$

1. Interaction of tenderization treatment and degree of doneness for tenderness ratings of the $M$. rectus femoris steaks cooked on a grill..

2. Interaction of tenderization treatment and degree of doneness for tenderness ratings of the $M$. semimembranosus steaks cooked in a skillet 


\section{LIST OF TABLES}

TABLE Page

1. Demographic background of consumers ....................................... 9

2. Least-squares means \pm SEM for consumer evaluations of beef steaks treated with blade tenderization or salt/phosphate injection

3. Least-squares means \pm SEM for consumer evaluations of beef steaks cooked with grilling, oven moist, cookery methods, or in a skillet

4. Least-squares means \pm SEM for consumer evaluations of beef steaks cooked on a grill

5. Least-squares means \pm SEM for consumer evaluations of beef steaks cooked using moist cookery

6. Least-squares means \pm SEM for consumer evaluations of beef steaks cooked in an oven

7. Least-squares means \pm SEM for consumer evaluations of beef steaks cooked in a skillet 


\section{CHAPTER I}

\section{INTRODUCTION AND REVIEW OF LITERATURE}

The beef industry is moving towards merchandising individual muscles, and has been focused on identifying and improving underutilized muscles from the round and chuck as a way to increase the value of the entire carcass. Past methods of merchandising beef round and chuck cuts by cutting steaks directly out of these large sub-primals created large portion sizes and multi-muscle cuts. This, in turn, led to a tremendous amount of variation in palatability caused by the variation of tenderness between the different muscles within each cut. Muscle profiling studies conducted by Belew, Brooks, McKenna, and Savell (2003) and Jones, Burson, and Calkins (2001) have been successful in identifying and characterizing those muscles that have a greater economic potential, but that have been traditionally merchandised as part of a larger, less consumer friendly cut. By separating out these individual muscles with an increased potential for acceptable palatability, the industry can focus on improving the palatability of those specific muscles.

Although palatability is a complex interaction of tenderness, juiciness, and flavor, many studies, including Dikeman (1987), have shown that tenderness may be the driving factor of the palatability equation. Huffman, Miller, Hoover, Wu, Brittin, and Ramsey (1996) found that consumers stated that tenderness was the attribute most

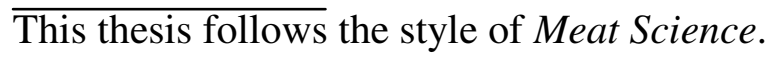


desired when eating a steak in the home or in a restaurant. Boleman et al. (1997) and Savell and Shackelford (1992) found that tenderness was the driving economic factor forbeef palatability. In Boleman et al. (1997), consumers were able to purchase steaks previously placed in a predetermined category of tenderness according to WarnerBratzler shear force values. After sampling them, consumers were not only able to distinguish the different categories of tenderness, but they also gave higher juiciness, flavor, and overall palatability ratings to those steaks in the highest tenderness (WarnerBratzler shear force values of $2.27-3.58 \mathrm{~kg}$ ) category. Although there was a $\$ 1.10 / \mathrm{kg}$ price difference between each of the three categories of tenderness, $94.6 \%$ of consumers bought steaks from the most tender category. This creates concerns with specific muscles from the round, as results from the muscle profiling studies showed that individual muscles from beef rounds were "intermediate" in tenderness when compared to the tenderness of all other muscles in the carcass. Lorenzen et al. (2003) reported that trained sensory panel ratings for top loin steaks were rated higher then top sirloin steaks, which were rated higher than top round steaks $(P<0.05)$ regardless of USDA quality grade. Also, Brooks et al. (2000) reported tenderness problems associated with muscles from beef rounds and Savell et al. (1989) found that the highest percentage of complaints about tenderness originated from top round steaks. These studies suggest that steaks from various round muscles are too tough, or at least to inconsistent in tenderness, to be considered acceptable to consumers. Because of this inconsistency in tenderness that is often observed in muscles from the round, it is expected that postmortem tenderization 
treatments will be required to improve the tenderness of these muscles to a point that meets consumer expectations.

Tenderization treatments, such as blade tenderization and injection with a salt/ phosphate solution, can help improve tenderness of beef steaks and roasts as well as help improve consistency in overall palatability. Savell, Smith, and Carpenter (1977), Mandigo and Olson (1982), and Glover, Forrest, Johnson, Bramblett, and Judge (1977) found that blade tenderization can improve beef tenderness. McGee, Henry, Brooks, Ray, and Morgan (2003) found that steaks that were injected were more tender $(P<$ 0.05) than control steaks in both Warner-Bratzler shear force and consumer sensory panel ratings. Kolle, McKenna, and Savell (2004) investigated the effects of blade tenderization, enzymatic tenderization, and injection with salt and phosphate solutions on individual muscles from beef rounds. Kolle et al. (2004) found that responses to tenderization systems were largely muscle dependent, with the M. gluteobiceps and $M$. semitendinosus showing little improvement in tenderness for any treatments. In contrast, the M. semimembranosus, M. adductor, M. rectus femoris, and M. vastus lateralis showed promising improvements in tenderness for all tenderization treatments evaluated used in this study. Determining which muscles will positively react to tenderization treatments has helped to focus on specific muscles in the round that can be further processed in order to increase their palatability and consumer appeal.

As mentioned earlier, most research has suggested that tenderness is the most important determinant of beef palatability, however, a steak that is lacking in any palatability criteria is likely to disappoint consumers. Several tenderization treatments 
have been noted as having some potentially negative impacts on other palatability characteristics. Increased purge loss and subsequent increased dryness have been described with blade tenderized steaks (Glover, Forrest, Johnson, Bramblett, \& Judge, 1977). Moreover, Miller (1998) suggested diluted flavor and mouthfeel changes potential problems with injected or enhanced meat products. Although tenderization treatments may help increase tenderness, they will not prove beneficial if they produce decreased palatability ratings from consumers as a result of any of these unintended side effects. Identifying any potential problems that may be associated with tenderization treatments will allow the industry to provide a product that is more likely to be accepted by the consumer.

Tenderization treatments may be meaningless if other palatability traits, such as juiciness or flavor, are compromised. In addition, if consumers are unable to detect differences in products when they are prepared as they would be at home, then there would be no benefit seen by the consumer. Consumer controlled factors, such as degree of doneness and cooking method, can have a great impact on consumer satisfaction (Lorenzen et al., 1999; Neely et al., 1999; and Savell et al., 1999). Neely et al. (1999) found that customer satisfaction with top round steaks is very dependent on how it is cooked and by whom it is consumed. Determining common cooking methods used by consumers may provide greater insight into the most beneficial tenderization treatment for individual round muscles.

Because consumer controlled factors such as these can play a big role in palatability, one of the limitations of objective measures of meat tenderness is that many 
factors that can influence tenderness, such as cooking method and degree of doneness, are controlled (Kolle et al., 2004). While these studies offer important information, they may not reflect how steaks from those muscles will perform when they are prepared by consumers using a variety of cooking methods and differing degrees of doneness. Inhome consumer evaluation studies have given excellent insights into how consumers prepare different types of steaks, what degree of doneness they prefer, and how these factors impact their satisfaction with beef products. An in-home study by Neely et al. (1998) found that stir-frying, braising, and simmering/stewing produced higher consumer ratings than other cooking methods, and steaks cooked to a medium rare and below and a very well done degree of doneness produced higher ratings than other degrees of doneness. This lead to the conclusion that low customer satisfaction ratings for top round steaks were observed primarily because consumers cooked with dry heat methods rather than moist heat (Neely et al., 1998). Subsequent marketing and educational campaigns have informed consumers of the proper methods to cook top rounds, and thus have increased customer satisfaction.

Of the muscles that responded positively to the various tenderization methods in Kolle et al. (2004), it is unclear which factors augment the existing palatability characteristics of the steaks from individual round muscles in the most beneficial way. An in-home study was conducted to give insight into consumer's ability to pick up both positive and negative effects of tenderization treatments, and subsequent tenderization recommendations can be made to retailers and processors so that muscles from beef rounds are tenderized in a manner that maximizes palatability. 


\section{CHAPTER II}

\section{MATERIALS AND METHODS}

\subsection{Processing}

USDA Select, Beef inside rounds (IMPS \#169A) $(\mathrm{n}=67)$ and knuckles (IMPS \# 167A) $(n=66)$ were purchased from a local processing facility and shipped to the Rosenthal Meat Science and Technology Center at Texas A\&M University. Subprimals complied (within packer variations) with Institutional Meat Purchase Specifications (IMPS) as described by USDA (1996) and NAMP (2003), and were assigned randomly to one of three treatments (control, blade tenderization, or injection with salt and phosphate solution). Inside rounds were separated into $M$. semimembranosus and $M$. adductor, and knuckles were separated into M. rectus femoris and M. vastus lateralis. Muscles were trimmed, defatted, and treated according to the group to which they were assigned.

\subsection{Tenderization treatments}

Final $\mathrm{pH}$ values for control muscles were $5.75 \pm 0.12,5.75 \pm 0.11,5.74 \pm 0.08$, and $5.75 \pm 0.08$ for the M. semimembranosus, M. adductor, M. rectus femoris, and $M$. vastus lateralis, respectively. The blade tenderization treatment consisted of a double pass through a 286 blade (13 rows of 22 blades) TEND-R-RITE Blade tenderizer (TR-2, Bettcher Industries, Inc., Birmingham, OH). Final $\mathrm{pH}$ values for post-processing blade 
tenderized muscles were $5.70 \pm 0.13,5.69 \pm 0.09,5.48 \pm 0.69$, and $5.51 \pm 0.05$ for the $M$. semimembranosus, $M$. adductor, $M$. rectus femoris, and $M$. vastus lateralis, respectively. The injection/enhancement treatment consisted of a water solution containing 5.0\% sodium chloride and $2.95 \%$ sodium tripolyphosphate (Brifisol ${ }^{\circledR} 512$, BK Giulini Corp., Simi Valley, CA). The solution $\left(\mathrm{pH} 7.61 \pm 0.23\right.$ at $\left.16.1^{\circ} \pm 1.07^{\circ} \mathrm{C}\right)$ was injected into the muscles at a $15 \%$ level using a single pass through a commercial injection machine (Inject Star BI 72, Inject Star, Inc., Brookfield, CT). Before steak cutting, muscles retained a $14.8 \% \pm 0.02,12.9 \% \pm 0.04,13.5 \% \pm 0.02$, and $13.9 \% \pm 0.04$ uptake for the M. semimembranosus, M. adductor, M. rectus femoris, and M. vastus lateralis, respectively. Final concentrations of sodium chloride and sodium tripolyphosphate in the muscles were estimated to be $0.71 \%$ and $0.42 \%$, respectively. Final post-processing $\mathrm{pH}$ values for injected muscles were $5.96 \pm 0.13,5.92 \pm 0.21,5.78 \pm 0.14$, and $5.89 \pm$ 0.17 for the M. semimembranosus, M. adductor, M. rectus femoris, and M. vastus lateralis, respectively. After processing, muscles were cut into $2.54 \mathrm{~cm}$ steaks, individually vacuum-packaged, and frozen. Three steaks were cut from each muscle perpendicular to the muscle fiber orientation starting from the most cranial aspect of each muscle and moving towards the most caudal aspect (or proximal and distal when appropriate).

\subsection{Consumer recruitment}

Steaks from each treatment group (control, blade tenderized, and injected) within a muscle from both muscles within a subprimal were assigned randomly to a corrugated 
cardboard box so that each box had six steaks (two muscles $\times$ three treatments). Each box also contained a survey with directions, a cooked beef color guide, a food safety guide, and a stamped, addressed envelope. Boxes were stored at $-10^{\circ} \mathrm{C}$ until delivery to consumers.

Beef consumers $(n=395)$ were solicited through direct contact by Texas A\&M University personnel (261 consumers completed the study). Participants were given a box of steaks and asked to prepare those steaks as they normally would if they had purchased them from the supermarket. Consumers were directed to cook only one steak per meal, per consumer, and it was suggested that they cook two steaks per week for a total of three weeks for timeliness purposes. Consumers were given a demographic questionnaire, which is summarized in Table 1. 
Table 1

Demographic background of consumers.

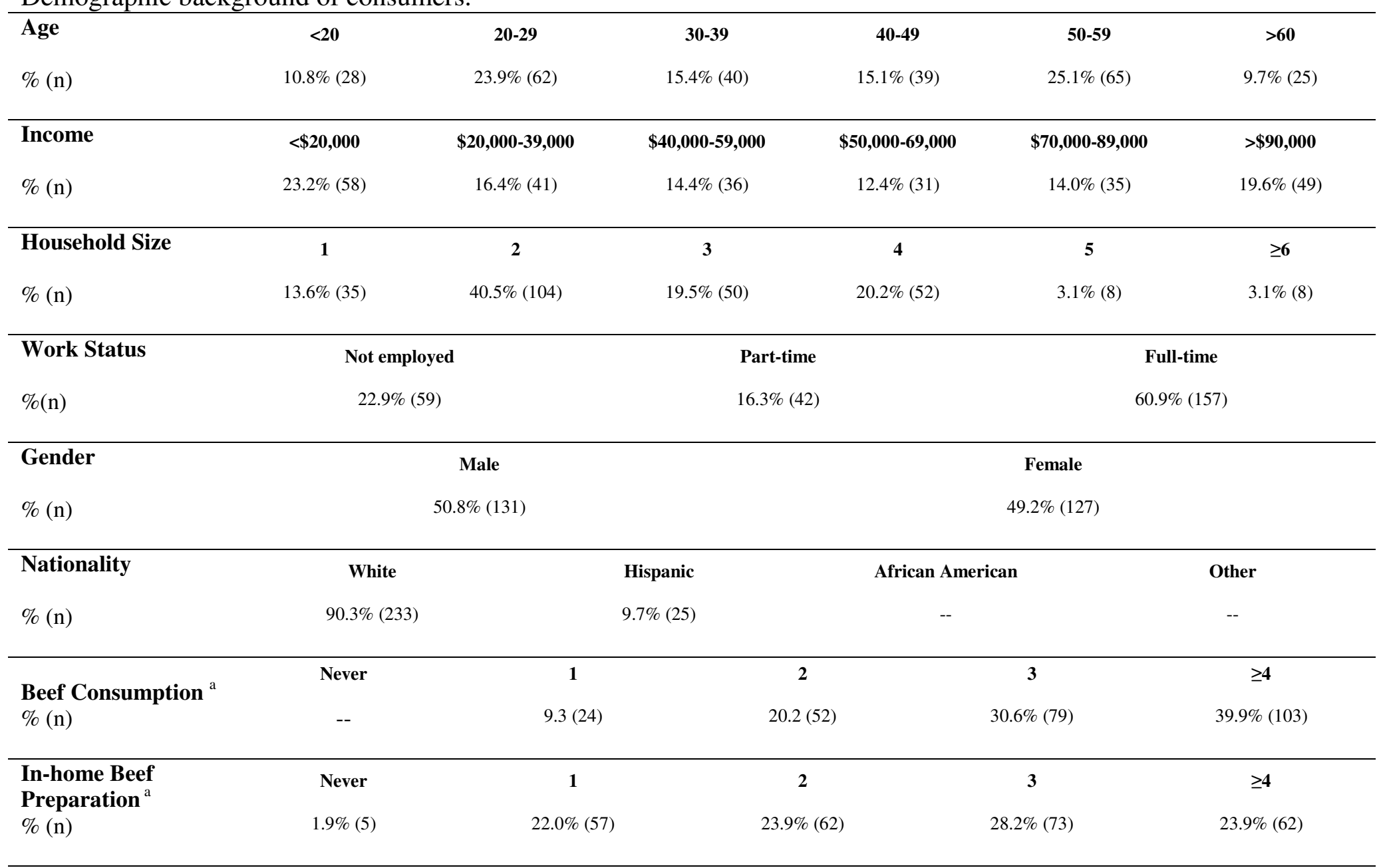

${ }^{\mathrm{a}}$ Consumption and preparation was reported as the number of times consumed per week. 
Preparers were asked to identify the cooking method used by referring to the definitions provided in the included directions. The cooking method definitions were as follows: outdoor grill- dry heat method, involving a grill to place meat on, over open flame or hot coals for cooking; indoor grill - dry heat method, dry heat cookery, involves placing meat on a small electric grill; pan-broil - dry heat cooking method, using medium to low heat in a skillet; pan-fry - dry heat method, using medium heat in a skillet with a small amount of oil, sometimes called sautéing; stir-fry - dry heat method, cooking slices of beef in a pan, usually with a small amount of oil, vegetables, and other ingredients, usually prepared in a Wok; broil - dry heat method, includes placing on a broiling pan in oven, allowing juices to drip away; oven roasted, uncovered - dry heat method, placing meat in a roasting pan or rack in the oven; braise and simmer - moist heat method, created by adding water to the pan, usually preformed in dutch oven or large skillet with a lid; stew - moist heat method, involves browning smaller pieces or cubes of meat and simmering in liquid over low-heat, covered (Bloch, 1977).

The approximate degree of doneness was determined by consumers using the National Cattlemen's Beef Association beef steak color guide provided for them in the box. The consumers were asked to evaluate steaks for overall-like, tenderness, juiciness, flavor intensity, and flavor desirability using a 10-point scale $(10=$ extreme like, extremely tender, extremely juicy, extremely intense, and extremely desirable; $1=$ extreme dislike, extremely tough, extremely dry, extremely bland, and extremely undesirable). Consumers were directed to fill out evaluation forms immediately after each meal and mail responses back to Texas A\&M University upon completion. This 
study was approved by the Institutional Review Board at Texas A\&M University, and informed consent was obtained from all participants.

\subsection{Statistical analysis}

Data were analyzed for each muscle individually using the PROC GLM procedure of SAS (SAS Institute, Cary, NC). Initial models tested the main effects of tenderization treatment and cooking method and their interaction. Cooking methods were pooled into four categories including: grill (outdoor and indoor grilling), oven (broil and oven roasted, uncovered), skillet (pan-broil, pan-fry, and stir-fry), and moist cookery (braise and simmer and stew). When interactions were not significant, they were removed from the model. Within cooking methods displaying sufficient numbers of steaks cooked to various degrees of doneness (grilling and skillet methods), the effects of degree of doneness and tenderization treatment were tested. If there was no interaction, only the degree of doneness means were presented as other means were presented in the previous analysis. A predetermined $\alpha$ of 0.05 was used for all determinations of statistical significance. 


\section{CHAPTER III}

\section{RESULTS AND DISCUSSION}

\subsection{Tenderization treatments}

Least-squares means for consumer evaluations of steaks are reported in Table 2. M. semimembranosus steaks from the salt/phosphate treatment received the highest $(P<$ 0.05) ratings for all traits compared to those from the control and blade tenderized treatments. For the $M$. rectus femoris, consumers gave steaks from the salt/phosphate treatment higher $(P<0.05)$ palatability ratings compared to control steaks, and higher $(P$ $<0.05)$ tenderness and juiciness ratings than steaks from the blade tenderized treatment. For the $M$. vastus lateralis, steaks from the salt/phosphate treatment received higher $(P<$ 0.05) palatability ratings for all traits compared to steaks from the blade tenderization treatment and the controls. In general, the salt/phosphate treatment resulted in improved palatability compared to the blade tenderized treatment and to the controls. In most cases, blade tenderizing did not improve palatability when compared to controls. 
Table 2

Least-squares means $\pm \mathrm{SEM}^{*}$ for consumer evaluations of beef steaks treated with blade tenderization or salt/phosphate injection.

\begin{tabular}{|c|c|c|c|c|c|}
\hline \multirow[b]{2}{*}{ Muscle } & \multirow[b]{2}{*}{ Attribute } & \multicolumn{3}{|c|}{ Treatment } & \multirow[b]{2}{*}{$P>\mathbf{F}$} \\
\hline & & Control & Blade & Inject & \\
\hline \multirow{5}{*}{ M. adductor } & Tenderness & $5.7 \pm 0.2$ & $6.2 \pm 0.2$ & $6.3 \pm 0.2$ & 0.06 \\
\hline & Juiciness & $5.4 \pm 0.2$ & $5.7 \pm 0.2$ & $6.0 \pm 0.2$ & 0.13 \\
\hline & Flavor Intensity & $5.9 \pm 0.2$ & $6.2 \pm 0.2$ & $6.3 \pm 0.2$ & 0.15 \\
\hline & Flavor Desirability & $6.0 \pm 0.2$ & $6.3 \pm 0.2$ & $6.3 \pm 0.2$ & 0.35 \\
\hline & Overall Like & $6.3 \pm 0.2$ & $6.8 \pm 0.2$ & $6.8 \pm 0.2$ & 0.10 \\
\hline \multirow[t]{5}{*}{ M. semimembranosus } & Tenderness & $6.0 \pm 0.2 b$ & $6.1 \pm 0.2 b$ & $6.6 \pm 0.2 \mathrm{a}$ & 0.04 \\
\hline & Juiciness & $5.5 \pm 0.2 b$ & $5.3 \pm 0.2 b$ & $6.2 \pm 0.2 \mathrm{a}$ & $<0.01$ \\
\hline & Flavor Intensity & $5.9 \pm 0.2 b$ & $6.0 \pm 0.2 b$ & $6.5 \pm 0.2 \mathrm{a}$ & 0.05 \\
\hline & Flavor Desirability & $6.0 \pm 0.2 b$ & $6.0 \pm 0.2 b$ & $6.7 \pm 0.2 \mathrm{a}$ & 0.01 \\
\hline & Overall Like & $6.4 \pm 0.2 b$ & $6.5 \pm 0.2 b$ & $7.1 \pm 0.2 \mathrm{a}$ & 0.02 \\
\hline \multirow[t]{5}{*}{ M. rectus femoris } & Tenderness & $6.3 \pm 0.2 b$ & $6.7 \pm 0.2 b$ & $7.2 \pm 0.2 \mathrm{a}$ & $<0.01$ \\
\hline & Juiciness & $5.9 \pm 0.2 b$ & $6.1 \pm 0.2 b$ & $6.9 \pm 0.2 \mathrm{a}$ & $<0.01$ \\
\hline & Flavor Intensity & $6.3 \pm 0.2 b$ & $6.5 \pm 0.2 \mathrm{ab}$ & $7.0 \pm 0.2 \mathrm{a}$ & 0.02 \\
\hline & Flavor Desirability & $6.2 \pm 0.2 b$ & $6.5 \pm 0.2 \mathrm{ab}$ & $6.9 \pm 0.2 \mathrm{a}$ & 0.02 \\
\hline & Overall Like & $6.5 \pm 0.2 b$ & $6.9 \pm 0.2 \mathrm{ab}$ & $7.3 \pm 0.2 \mathrm{a}$ & $<0.01$ \\
\hline \multirow{5}{*}{ M. vastus lateralis } & Tenderness & $5.4 \pm 0.2 b$ & $5.7 \pm 0.2 b$ & $6.5 \pm 0.2 \mathrm{a}$ & $<0.01$ \\
\hline & Juiciness & $5.3 \pm 0.2 b$ & $5.6 \pm 0.2 b$ & $6.2 \pm 0.2 \mathrm{a}$ & 0.01 \\
\hline & Flavor Intensity & $5.5 \pm 0.2 b$ & $5.8 \pm 0.2 b$ & $6.6 \pm 0.2 \mathrm{a}$ & $<0.01$ \\
\hline & Flavor Desirability & $5.6 \pm 0.2 b$ & $6.0 \pm 0.2 b$ & $6.7 \pm 0.2 a$ & $<0.01$ \\
\hline & Overall Like & $5.8 \pm 0.2 b$ & $6.1 \pm 0.2 b$ & $6.9 \pm 0.2 \mathrm{a}$ & $<0.01$ \\
\hline
\end{tabular}

Means within the same row lacking common letters $(\mathrm{a}, \mathrm{b})$ differ $(P<0.05)$.

*SEM is the standard error of the least squares means. 


\subsection{Cooking methods}

When considering at the various cooking methods (Table 3), M. adductor steaks cooked in the skillet and using a grilling method received higher $(P<0.05)$ consumer ratings for juiciness than steaks cooked in an oven or using moist cookery. For flavor intensity and desirability, steaks cooked in a skillet, on the grill, and in the oven were ranked higher $(P<0.05)$ than those cooked using moist cookery. This might suggest that cooking with moist heat cookery can reduce the flavor attributes of the $M$. adductor steak to an unacceptable level for consumers. For $M$. rectus femoris steaks, tenderness ratings were higher $(P<0.05)$ for those steaks cooked using moist cookery and in a skillet than those cooked in an oven or on a grill. For M. vastus lateralis, the steaks cooked with moist cookery were given higher ratings $(P<0.05)$ for tenderness, whereas those cooked on a skillet, in the oven, or on a grill, were given similar and lower ratings. The increase in tenderness of the $M$. vastus lateralis steaks cooked using moist heat also created higher $(P<0.05)$ ratings for overall like, suggesting that the role that moist heat cookery played in increasing tenderness also increased the overall palatability of the steak for consumers.

In general, cooking methods did not provide substantial increases in consumer palatability attributes. For the knuckle steaks (M. rectus femoris and M. vastus lateralis), moist-heat cookery did create an increase in tenderness ratings from consumers as compared to dry heat methods (grill and oven). 
Table 3

Least-squares means $\pm \mathrm{SEM}^{*}$ for consumer evaluations of beef steaks cooked with grilling, oven moist, cookery methods, or in a skillet.

\begin{tabular}{|c|c|c|c|c|c|c|}
\hline \multirow[b]{2}{*}{ Muscle } & \multirow[b]{2}{*}{ Attribute } & \multicolumn{4}{|c|}{ Cooking Method } & \multirow[b]{2}{*}{$P>\mathbf{F}$} \\
\hline & & Grill & Oven & Moist & Skillet & \\
\hline \multirow[t]{5}{*}{ M. adductor } & Tenderness & $6.1 \pm 0.2$ & $6.1 \pm 0.3$ & $5.7 \pm 0.4$ & $6.5 \pm 0.2$ & 0.17 \\
\hline & Juiciness & $6.0 \pm 0.2 \mathrm{ab}$ & $5.4 \pm 0.3 b$ & $5.3 \pm 0.4 b$ & $6.2 \pm 0.2 \mathrm{a}$ & 0.05 \\
\hline & Flavor Intensity & $6.4 \pm 0.1 \mathrm{a}$ & $6.2 \pm 0.3 \mathrm{ab}$ & $5.4 \pm 0.4 b$ & $6.6 \pm 0.2 \mathrm{a}$ & 0.02 \\
\hline & Flavor Desirability & $6.3 \pm 0.1 \mathrm{a}$ & $6.4 \pm 0.3 a$ & $5.4 \pm 0.4 b$ & $6.7 \pm 0.2 \mathrm{a}$ & 0.02 \\
\hline & Overall Like & $6.4 \pm 0.1$ & $6.8 \pm 0.3$ & $6.4 \pm 0.4$ & $6.9 \pm 0.2$ & 0.21 \\
\hline \multirow[t]{5}{*}{ M. semimembranosus } & Tenderness & $5.9 \pm 0.1$ & $6.3 \pm 0.4$ & $6.6 \pm 0.4$ & $6.0 \pm 0.2$ & 0.33 \\
\hline & Juiciness & $5.8 \pm 0.2$ & $5.4 \pm 0.4$ & $5.8 \pm 0.4$ & $5.6 \pm 0.2$ & 0.72 \\
\hline & Flavor Intensity & $6.1 \pm 0.1$ & $6.1 \pm 0.3$ & $6.4 \pm 0.4$ & $6.1 \pm 0.2$ & 0.90 \\
\hline & Flavor Desirability & $6.1 \pm 0.1$ & $6.2 \pm 0.4$ & $6.4 \pm 0.4$ & $6.2 \pm 0.2$ & 0.91 \\
\hline & Overall Like & $6.5 \pm 0.2$ & $6.8 \pm 0.3$ & $7.0 \pm 0.3$ & $6.4 \pm 0.2$ & 0.38 \\
\hline \multirow[t]{5}{*}{ M. rectus femoris } & Tenderness & $6.4 \pm 0.2 b$ & $6.3 \pm 0.4 b$ & $7.2 \pm 0.3 a$ & $6.9 \pm 0.2 \mathrm{a}$ & 0.03 \\
\hline & Juiciness & $6.3 \pm 0.2$ & $5.9 \pm 0.4$ & $6.6 \pm 0.3$ & $6.6 \pm 0.2$ & 0.26 \\
\hline & Flavor Intensity & $6.4 \pm 0.2$ & $6.3 \pm 0.4$ & $6.8 \pm 0.3$ & $6.9 \pm 0.2$ & 0.29 \\
\hline & Flavor Desirability & $6.4 \pm 0.2$ & $6.2 \pm 0.4$ & $6.7 \pm 0.3$ & $6.8 \pm 0.2$ & 0.21 \\
\hline & Overall Like & $6.7 \pm 0.1$ & $6.6 \pm 0.3$ & $7.2 \pm 0.3$ & $7.1 \pm 0.2$ & 0.21 \\
\hline \multirow[t]{5}{*}{ M. vastus lateralis } & Tenderness & $5.6 \pm 0.2 b$ & $5.1 \pm 0.3 b$ & $7.1 \pm 0.3 a$ & $5.6 \pm 0.2 b$ & $<0.01$ \\
\hline & Juiciness & $5.7 \pm 0.2$ & $5.3 \pm 0.4$ & $6.1 \pm 0.3$ & $5.7 \pm 0.2$ & 0.40 \\
\hline & Flavor Intensity & $6.1 \pm 0.2$ & $5.4 \pm 0.3$ & $6.2 \pm 0.3$ & $6.1 \pm 0.2$ & 0.26 \\
\hline & Flavor Desirability & $5.9 \pm 0.2$ & $5.7 \pm 0.3$ & $6.6 \pm 0.3$ & $6.2 \pm 0.2$ & 0.21 \\
\hline & Overall Like & $6.1 \pm 0.2 b$ & $5.7 \pm 0.3 b$ & $7.1 \pm 0.3 \mathrm{a}$ & $6.1 \pm 0.2 b$ & 0.01 \\
\hline
\end{tabular}

Means within the same row lacking common letters $(\mathrm{a}, \mathrm{b})$ differ $(P<0.05)$.

*SEM is the standard error of the least squares means. 


\subsection{Degree of doneness}

M. semimembranosus steaks cooked on a grill (Table 4) to a degree of doneness of medium rare and below received the highest $(P<0.05)$ ratings for juiciness, flavor intensity, and desirability. The degree of doneness clearly influenced consumer palatability ratings for $M$. rectus femoris steaks cooked on a grill. Lower degrees of doneness (medium rare and below and medium) received higher $(P<0.05)$ tenderness ratings than steaks cooked to well done. Juiciness ratings increased as the degree of doneness decreased, with steaks cooked to medium rare or below receiving higher $(P<$ $0.05)$ ratings than those cooked to medium well. In addition, those steaks cooked to medium well produced higher $(P<0.05)$ juiciness ratings than those cooked to well done. Steaks cooked to medium rare and below received the highest $(P<0.05)$ ratings for flavor intensity. Flavor desirability and overall like ratings received similar ratings as those steaks cooked to medium rare and below. For overall like, there was an interaction between tenderization treatment and degree of doneness (Figure 1).

In general, lower degrees of doneness produced higher palatability ratings. This, combined with other findings, suggest that a dry heat cookery method like grilling may be acceptable for the $M$. rectus femoris if cooked to lower degrees of doneness. 
Table 4

Least-squares means $\pm \mathrm{SEM}^{*}$ for consumer evaluations of beef steaks cooked on a grill.

\begin{tabular}{|c|c|c|c|c|c|c|}
\hline \multirow[b]{2}{*}{ Muscle } & \multirow[b]{2}{*}{ Attribute } & \multicolumn{4}{|c|}{ Degree of Doneness } & \multirow[b]{2}{*}{$P>\mathbf{F}$} \\
\hline & & $\begin{array}{l}\text { Med Rare } \\
\text { and Rare }\end{array}$ & Medium & Medium Well & Well Done & \\
\hline \multirow[t]{5}{*}{ M. adductor } & Tenderness & $5.8 \pm 0.4$ & $5.7 \pm 0.3$ & $6.4 \pm 0.3$ & $6.4 \pm 0.3$ & 0.22 \\
\hline & Juiciness & $5.9 \pm 0.4$ & $5.7 \pm 0.3$ & $6.2 \pm 0.3$ & $6.1 \pm 0.4$ & 0.67 \\
\hline & Flavor Intensity & $6.5 \pm 0.4$ & $6.2 \pm 0.2$ & $6.7 \pm 0.2$ & $6.3 \pm 0.3$ & 0.36 \\
\hline & Flavor Desirability & $6.4 \pm 0.4$ & $6.0 \pm 0.3$ & $6.6 \pm 0.3$ & $6.1 \pm 0.3$ & 0.36 \\
\hline & Overall Like & $6.1 \pm 0.4$ & $6.1 \pm 0.2$ & $6.7 \pm 0.2$ & $6.8 \pm 0.3$ & 0.22 \\
\hline \multirow[t]{5}{*}{ M. semimembranosus } & Tenderness & $6.8 \pm 0.4$ & $5.8 \pm 0.2$ & $5.6 \pm 0.3$ & $6.0 \pm 0.3$ & 0.09 \\
\hline & Juiciness & $7.0 \pm 0.4 \mathrm{a}$ & $5.9 \pm 0.3$ & $5.7 \pm 0.3 b$ & $5.1 \pm 0.4 b$ & $<0.01$ \\
\hline & Flavor Intensity & $7.3 \pm 0.4 \mathrm{a}$ & $6.0 \pm 0.2 b$ & $5.7 \pm 0.2 b$ & $5.8 \pm 0.3 b$ & $<0.01$ \\
\hline & Flavor Desirability & $7.4 \pm 0.4 a$ & $6.0 \pm 0.2 b$ & $5.8 \pm 0.3 b$ & $5.9 \pm 0.3 b$ & 0.01 \\
\hline & Overall Like & $7.1 \pm 0.4$ & $6.4 \pm 0.2$ & $6.4 \pm 0.2$ & $6.4 \pm 0.3$ & 0.38 \\
\hline \multirow[t]{5}{*}{ M. rectus femoris } & Tenderness & $6.9 \pm 0.3 a$ & $6.6 \pm 0.3 a$ & $6.2 \pm 0.3 \mathrm{ab}$ & $5.5 \pm 0.4 b$ & 0.04 \\
\hline & Juiciness & $7.2 \pm 0.3 \mathrm{a}$ & $6.5 \pm 0.3 \mathrm{ab}$ & $6.0 \pm 0.3 b$ & $4.3 \pm 0.4 c$ & $<0.01$ \\
\hline & Flavor Intensity & $7.4 \pm 0.3 \mathrm{a}$ & $6.4 \pm 0.3 b$ & $6.0 \pm 0.3 b$ & $5.7 \pm 0.4 b$ & $<0.01$ \\
\hline & Flavor Desirability & $7.2 \pm 0.3 \mathrm{a}$ & $6.5 \pm 0.3 \mathrm{ab}$ & $5.9 \pm 0.3 b$ & $5.4 \pm 0.4 b$ & 0.01 \\
\hline & Overall Like & $7.2 \pm 0.3 \mathrm{a}$ & $6.9 \pm 0.2 \mathrm{ab}$ & $6.3 \pm 0.3 b$ & $6.1 \pm 0.4 b$ & 0.05 \\
\hline \multirow[t]{5}{*}{ M. vastus lateralis } & Tenderness & $5.5 \pm 0.3$ & $5.8 \pm 0.3$ & $5.1 \pm 0.3$ & $6.7 \pm 0.5$ & 0.07 \\
\hline & Juiciness & $6.1 \pm 0.4$ & $5.9 \pm 0.3$ & $5.2 \pm 0.3$ & $5.2 \pm 0.5$ & 0.18 \\
\hline & Flavor Intensity & $6.1 \pm 0.3$ & $6.1 \pm 0.3$ & $5.7 \pm 0.3$ & $7.0 \pm 0.5$ & 0.22 \\
\hline & Flavor Desirability & $5.9 \pm 0.4$ & $6.1 \pm 0.3$ & $5.4 \pm 0.3$ & $7.0 \pm 0.5$ & 0.10 \\
\hline & Overall Like & $6.1 \pm 0.3$ & $6.2 \pm 0.3$ & $5.6 \pm 0.3$ & $6.9 \pm 0.5$ & 0.20 \\
\hline
\end{tabular}

Means within the same row lacking common letters $(\mathrm{a}-\mathrm{c})$ differ $(P<0.05)$.

*SEM is the standard error of the least squares means. 


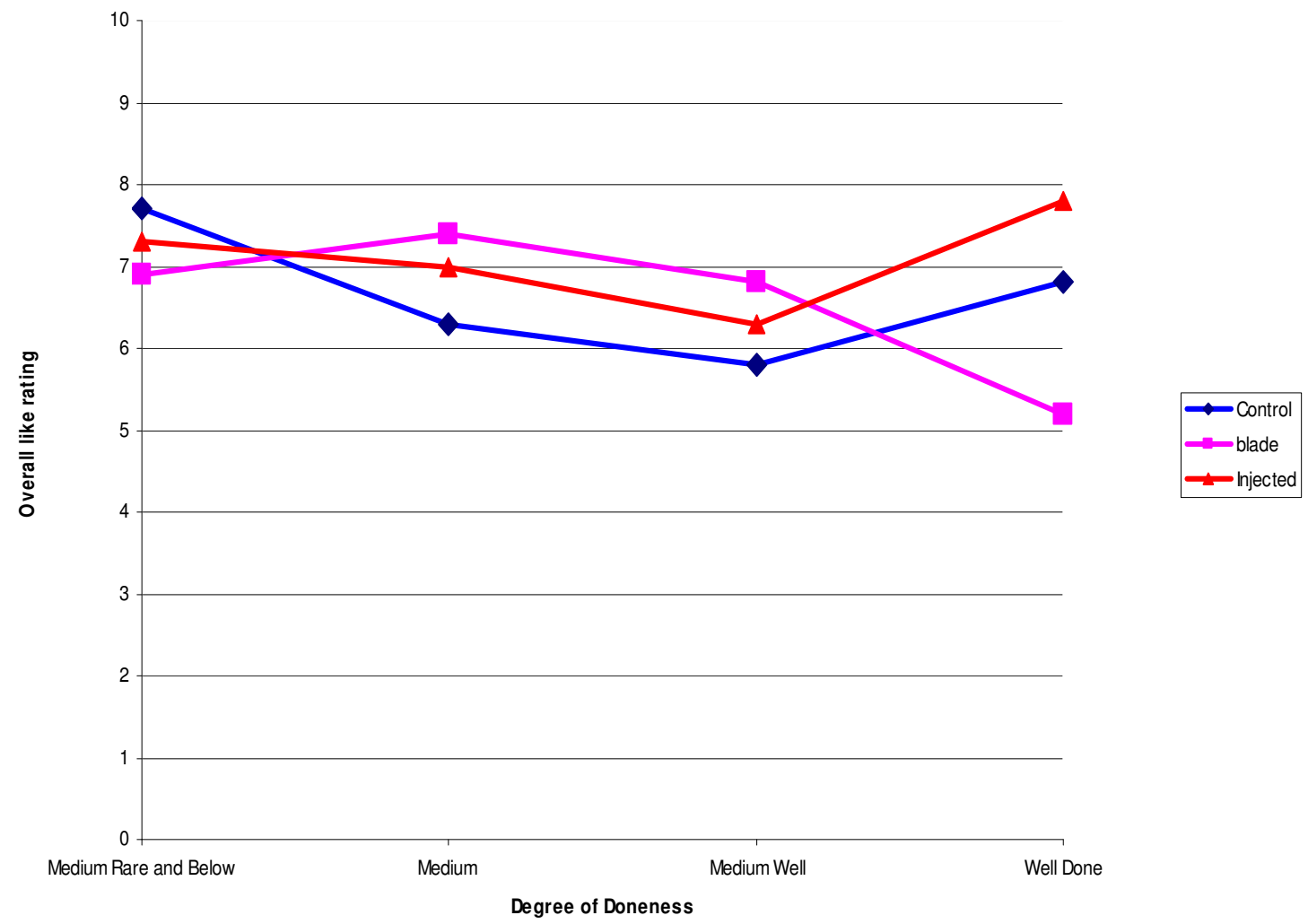

Figure 1. Interaction of tenderization treatment and degree of doneness for tenderness ratings of the $M$. rectus femoris steaks cooked on a grill.

In Table 5, least-squares means for consumer evaluations of steaks cooked using moist cookery are presented. For the attribute of overall like, consumers rated those $M$. semimembranosus steaks cooked medium rare and below the lowest $(P<0.05)$. 
Table 5

Least-squares means $\pm \mathrm{SEM}^{*}$ for consumer evaluations of beef steaks cooked using moist cookery.

\begin{tabular}{|c|c|c|c|c|c|c|}
\hline \multirow[b]{2}{*}{ Muscle } & \multirow[b]{2}{*}{ Attribute } & \multicolumn{4}{|c|}{ Degree of Doneness } & \multirow[b]{2}{*}{$P>\mathbf{F}$} \\
\hline & & $\begin{array}{l}\text { Med Rare and } \\
\text { Rare }\end{array}$ & Medium & Medium Well & Well Done & \\
\hline \multirow[t]{5}{*}{ M. adductor } & Tenderness & - & $4.7 \pm 1.2$ & $4.9 \pm 0.8$ & $6.1 \pm 0.5$ & 0.32 \\
\hline & Juiciness & - & $4.7 \pm 1.1$ & $4.9 \pm 0.7$ & $5.4 \pm 0.5$ & 0.76 \\
\hline & Flavor Intensity & - & $5.0 \pm 1.0$ & $5.4 \pm 0.7$ & $5.3 \pm 0.4$ & 0.95 \\
\hline & Flavor Desirability & - & $5.0 \pm 1.1$ & $4.3 \pm 0.8$ & $5.8 \pm 0.5$ & 0.24 \\
\hline & Overall Like & - & $5.3 \pm 1.0$ & $6.7 \pm 0.6$ & $6.4 \pm 0.4$ & 0.52 \\
\hline \multirow[t]{5}{*}{ M. semimembranosus } & Tenderness & $1.1 \pm 2.0$ & $7.8 \pm 1.2$ & $6.3 \pm 0.9$ & $6.8 \pm 0.4$ & 0.06 \\
\hline & Juiciness & $2.5 \pm 2.4$ & $7.3 \pm 1.4$ & $5.6 \pm 1.1$ & $5.8 \pm 0.5$ & 0.41 \\
\hline & Flavor Intensity & $3.1 \pm 2.1$ & $6.5 \pm 1.2$ & $5.7 \pm 1.0$ & $6.6 \pm 0.4$ & 0.34 \\
\hline & Flavor Desirability & $2.0 \pm 2.0$ & $6.7 \pm 1.2$ & $6.0 \pm 1.0$ & $6.7 \pm 0.4$ & 0.17 \\
\hline & Overall Like & $2.0 \pm 2.0 \mathrm{~b}$ & $8.7 \pm 1.2 \mathrm{a}$ & $6.1 \pm 0.9 a$ & $7.1 \pm 0.4 \mathrm{a}$ & 0.05 \\
\hline \multirow[t]{5}{*}{ M. rectus femoris } & Tenderness & $7.0 \pm 2.1$ & $6.9 \pm 1.0$ & $7.3 \pm 0.5$ & $7.4 \pm 0.4$ & 0.98 \\
\hline & Juiciness & $5.1 \pm 2.4$ & $5.4 \pm 1.1$ & $6.8 \pm 0.6$ & $6.9 \pm 0.5$ & 0.54 \\
\hline & Flavor Intensity & $4.5 \pm 2.4$ & $5.5 \pm 1.1$ & $7.6 \pm 0.6$ & $6.8 \pm 0.4$ & 0.29 \\
\hline & Flavor Desirability & $3.7 \pm 2.3$ & $5.2 \pm 1.1$ & $7.5 \pm 0.6$ & $6.9 \pm 0.4$ & 0.17 \\
\hline & Overall Like & $5.9 \pm 2.0$ & $6.1 \pm 0.9$ & $7.1 \pm 0.5$ & $7.7 \pm 0.4$ & 0.33 \\
\hline \multirow[t]{5}{*}{ M. vastus lateralis } & Tenderness & $7.8 \pm 1.6$ & $6.2 \pm 0.8$ & $6.9 \pm 0.6$ & $7.4 \pm 0.5$ & 0.63 \\
\hline & Juiciness & $8.4 \pm 1.7$ & $5.2 \pm 0.9$ & $6.3 \pm 0.6$ & $5.8 \pm 0.5$ & 0.39 \\
\hline & Flavor Intensity & $8.4 \pm 1.3$ & $4.7 \pm 0.7$ & $6.6 \pm 0.5$ & $6.1 \pm 0.4$ & 0.06 \\
\hline & Flavor Desirability & $8.3 \pm 1.5$ & $4.9 \pm 0.8$ & $6.8 \pm 0.5$ & $6.7 \pm 0.5$ & 0.15 \\
\hline & Overall Like & $8.3 \pm 1.4$ & $6.4 \pm 0.7$ & $7.2 \pm 0.5$ & $7.1 \pm 0.4$ & 0.57 \\
\hline
\end{tabular}

Means within the same row lacking common letters $(\mathrm{a}, \mathrm{b})$ differ $(P<0.05)$.

*SEM is the standard error of the least squares means. 
Consumers who prepared $M$. semimembranosus steaks in an oven (Table 6) ranked steaks cooked to medium rare and below higher $(P<0.05)$ than those cooked to medium well and well done for overall like. For M. rectus femoris steaks cooked in an oven to medium rare and below, higher ratings $(P<0.05)$ were given for juiciness than for all other attributes. For M. vastus lateralis steaks cooked in an oven, ratings for juiciness and overall like were higher $(P<0.05)$ for steaks cooked to medium rare and below than those cooked to medium well, and lowest $(P<0.05)$ for those cooked well done. For flavor intensity, those cooked to medium rare and below and medium were rated higher $(P<0.05)$ than those cooked well done. Ratings for overall like patterned those for juiciness, signifying that juiciness played an important role in the overall palatability of a round steak when cooked using a dry heat method. 
Table 6

Least-squares means $\pm \mathrm{SEM}^{*}$ for consumer evaluations of beef steaks cooked in an oven.

\begin{tabular}{|c|c|c|c|c|c|c|}
\hline \multirow[b]{2}{*}{ Muscle } & \multirow[b]{2}{*}{ Attribute } & \multicolumn{4}{|c|}{ Degree of Doneness } & \multirow[b]{2}{*}{$P>\mathbf{F}$} \\
\hline & & $\begin{array}{c}\text { Med Rare and } \\
\text { Rare }\end{array}$ & Medium & $\begin{array}{c}\text { Medium } \\
\text { Well }\end{array}$ & Well Done & \\
\hline \multirow{5}{*}{ M. adductor } & Tenderness & $5.3 \pm 1.1$ & $6.4 \pm 0.7$ & $5.9 \pm 0.7$ & $6.3 \pm 0.6$ & 0.79 \\
\hline & Juiciness & $6.0 \pm 1.3$ & $6.1 \pm 0.8$ & $5.7 \pm 0.8$ & $4.4 \pm 0.7$ & 0.36 \\
\hline & Flavor Intensity & $6.0 \pm 1.2$ & $6.5 \pm 0.7$ & $6.8 \pm 0.8$ & $5.5 \pm 0.6$ & 0.57 \\
\hline & Flavor Desirability & $6.6 \pm 1.2$ & $6.8 \pm 0.7$ & $6.7 \pm 0.8$ & $6.0 \pm 0.6$ & 0.83 \\
\hline & Overall Like & $6.5 \pm 1.0$ & $7.0 \pm 0.6$ & $6.6 \pm 0.7$ & $7.1 \pm 0.5$ & 0.92 \\
\hline \multirow[t]{5}{*}{ M. semimembranosus } & Tenderness & $5.2 \pm 0.9$ & $7.0 \pm 0.8$ & $5.4 \pm 1.0$ & $6.5 \pm 0.6$ & 0.37 \\
\hline & Juiciness & $5.2 \pm 1.0$ & $6.8 \pm 0.8$ & $4.4 \pm 1.1$ & $5.1 \pm 0.7$ & 0.31 \\
\hline & Flavor Intensity & $5.6 \pm 1.0$ & $7.2 \pm 0.8$ & $5.0 \pm 1.0$ & $6.1 \pm 0.6$ & 0.35 \\
\hline & Flavor Desirability & $5.1 \pm 0.9$ & $7.0 \pm 0.8$ & $5.2 \pm 1.0$ & $6.5 \pm 0.6$ & 0.31 \\
\hline & Overall Like & $5.8 \pm 0.6 b$ & $6.9 \pm 0.6 \mathrm{ab}$ & $5.6 \pm 0.7 b$ & $7.7 \pm 0.4 \mathrm{a}$ & 0.04 \\
\hline \multirow[t]{5}{*}{ M. rectus femoris } & Tenderness & $7.4 \pm 0.8$ & $6.7 \pm 0.5$ & $6.3 \pm 0.5$ & $5.4 \pm 0.6$ & 0.21 \\
\hline & Juiciness & $7.9 \pm 0.7 \mathrm{a}$ & $6.1 \pm 0.4 b$ & $5.3 \pm 0.5 b$ & $5.2 \pm 0.5 b$ & 0.03 \\
\hline & Flavor Intensity & $7.4 \pm 0.8$ & $6.7 \pm 0.5$ & $5.9 \pm 0.5$ & $5.9 \pm 0.6$ & 0.32 \\
\hline & Flavor Desirability & $7.6 \pm 0.8$ & $6.4 \pm 0.5$ & $6.0 \pm 0.5$ & $5.3 \pm 0.6$ & 0.13 \\
\hline & Overall Like & $8.2 \pm 0.8$ & $6.6 \pm 0.4$ & $6.4 \pm 0.5$ & $6.0 \pm 0.6$ & 0.17 \\
\hline \multirow[t]{5}{*}{ M. vastus lateralis } & Tenderness & $6.1 \pm 0.6$ & $5.6 \pm 0.5$ & $4.6 \pm 0.5$ & $3.8 \pm 0.7$ & 0.06 \\
\hline & Juiciness & $6.7 \pm 0.5 \mathrm{a}$ & $5.6 \pm 0.5 \mathrm{ab}$ & $5.1 \pm 0.5 b$ & $3.3 \pm 0.6 c$ & $<0.01$ \\
\hline & Flavor Intensity & $6.3 \pm 0.6 a$ & $6.1 \pm 0.5 \mathrm{a}$ & $5.0 \pm 0.5 \mathrm{ab}$ & $4.0 \pm 0.6 b$ & 0.02 \\
\hline & Flavor Desirability & $7.2 \pm 0.6 \mathrm{a}$ & $6.2 \pm 0.5 \mathrm{ab}$ & $5.0 \pm 0.5 b$ & $4.4 \pm 0.6 b$ & 0.01 \\
\hline & Overall Like & $6.7 \pm 0.6 a$ & $6.1 \pm 0.5 \mathrm{ab}$ & $5.1 \pm 0.5 b$ & $4.1 \pm 0.6 c$ & 0.02 \\
\hline
\end{tabular}

Means within the same row lacking common letters (a-c) differ $(P<0.05)$

*SEM is the standard error of the least squares means. 
M. adductor steaks cooked in a skillet to a well done degree of doneness received lower $(P<0.05)$ ratings for juiciness than those cooked to medium rare and below and those cooked to medium well (Table 7). For M. vastus lateralis steaks cooked in a skillet, juiciness ratings were higher $(P<0.05)$ for those steaks cooked to medium rare and below than for those cooked to medium well and well done. Although there were no significant $(P>0.05)$ degree of doneness effects on palatability ratings for the $M$. semimembranosus cooked in a skillet, there was an interaction for tenderness between tenderization treatment and degree of doneness (Figure 2). 
Table 7

Least-squares means $\pm \mathrm{SEM}^{*}$ for consumer evaluations of beef steaks cooked in a skillet.

\begin{tabular}{|c|c|c|c|c|c|c|}
\hline \multirow[b]{2}{*}{ Muscle } & \multirow[b]{2}{*}{ Attribute } & \multicolumn{4}{|c|}{ Degree of Doneness } & \multirow[b]{2}{*}{$P>\mathbf{F}$} \\
\hline & & $\begin{array}{c}\text { Med Rare and } \\
\text { Rare }\end{array}$ & Medium & $\begin{array}{c}\text { Medium } \\
\text { Well }\end{array}$ & Well Done & \\
\hline \multirow[t]{5}{*}{ M. adductor } & Tenderness & $6.8 \pm 0.6$ & $6.7 \pm 0.3$ & $6.8 \pm 0.3$ & $6.1 \pm 0.3$ & 0.47 \\
\hline & Juiciness & $7.3 \pm 0.6 \mathrm{a}$ & $6.3 \pm 0.3 \mathrm{ab}$ & $6.6 \pm 0.3 a$ & $5.6 \pm 0.3 b$ & 0.03 \\
\hline & Flavor Intensity & $7.3 \pm 0.6$ & $6.6 \pm 0.4$ & $7.0 \pm 0.4$ & $6.1 \pm 0.3$ & 0.19 \\
\hline & $\begin{array}{l}\text { Flavor } \\
\text { Desirability }\end{array}$ & $7.3 \pm 0.6$ & $6.5 \pm 0.3$ & $7.1 \pm 0.3$ & $6.4 \pm 0.3$ & 0.43 \\
\hline & Overall Like & $7.5 \pm 0.6$ & $6.9 \pm 0.3$ & $7.3 \pm 0.3$ & $6.5 \pm 0.3$ & 0.29 \\
\hline \multirow[t]{5}{*}{ M. semimembranosus } & Tenderness & $5.2 \pm 0.5$ & $6.0 \pm 0.4$ & $6.5 \pm 0.4$ & $5.9 \pm 0.4$ & 0.32 \\
\hline & Juiciness & $5.6 \pm 0.5$ & $5.9 \pm 0.4$ & $5.7 \pm 0.4$ & $5.4 \pm 0.4$ & 0.74 \\
\hline & Flavor Intensity & $6.3 \pm 0.5$ & $6.2 \pm 0.3$ & $6.2 \pm 0.4$ & $5.9 \pm 0.4$ & 0.94 \\
\hline & $\begin{array}{l}\text { Flavor } \\
\text { Desirability }\end{array}$ & $5.9 \pm 0.5$ & $6.2 \pm 0.4$ & $6.1 \pm 0.4$ & $6.3 \pm 0.4$ & 0.94 \\
\hline & Overall Like & $5.4 \pm 0.5$ & $6.3 \pm 0.4$ & $6.8 \pm 0.4$ & $6.5 \pm 0.4$ & 0.24 \\
\hline \multirow[t]{5}{*}{ M. rectus femoris } & Tenderness & $6.7 \pm 0.5$ & $7.3 \pm 0.3$ & $6.7 \pm 0.3$ & $6.9 \pm 0.4$ & 0.57 \\
\hline & Juiciness & $7.5 \pm 0.5$ & $6.6 \pm 0.3$ & $6.4 \pm 0.3$ & $6.0 \pm 0.4$ & 0.11 \\
\hline & Flavor Intensity & $7.5 \pm 0.5$ & $6.8 \pm 0.3$ & $6.9 \pm 0.3$ & $6.5 \pm 0.4$ & 0.53 \\
\hline & $\begin{array}{l}\text { Flavor } \\
\text { Desirability }\end{array}$ & $7.1 \pm 0.5$ & $6.9 \pm 0.4$ & $6.7 \pm 0.3$ & $6.7 \pm 0.4$ & 0.91 \\
\hline & Overall Like & $7.6 \pm 0.5$ & $7.1 \pm 0.3$ & $6.8 \pm 0.3$ & $7.0 \pm 0.4$ & 0.52 \\
\hline \multirow[t]{5}{*}{ M. vastus lateralis } & Tenderness & $5.9 \pm 0.5$ & $5.7 \pm 0.4$ & $5.7 \pm 0.3$ & $4.8 \pm 0.4$ & 0.24 \\
\hline & Juiciness & $6.7 \pm 0.5 a$ & $5.9 \pm 0.4 \mathrm{ab}$ & $5.4 \pm 0.4 b$ & $4.9 \pm 0.4 b$ & 0.04 \\
\hline & Flavor Intensity & $6.8 \pm 0.4$ & $6.1 \pm 0.4$ & $6.3 \pm 0.3$ & $5.4 \pm 0.4$ & 0.10 \\
\hline & $\begin{array}{l}\text { Flavor } \\
\text { Desirability }\end{array}$ & $6.7 \pm 0.5$ & $6.1 \pm 0.4$ & $6.3 \pm 0.4$ & $5.7 \pm 0.4$ & 0.46 \\
\hline & Overall Like & $6.5 \pm 0.5$ & $6.1 \pm 0.4$ & $6.4 \pm 0.4$ & $5.4 \pm 0.4$ & 0.28 \\
\hline
\end{tabular}

Means within the same row lacking common letters $(\mathrm{a}, \mathrm{b})$ differ $(P<0.05)$.

*SEM is the standard error of the least squares means. 


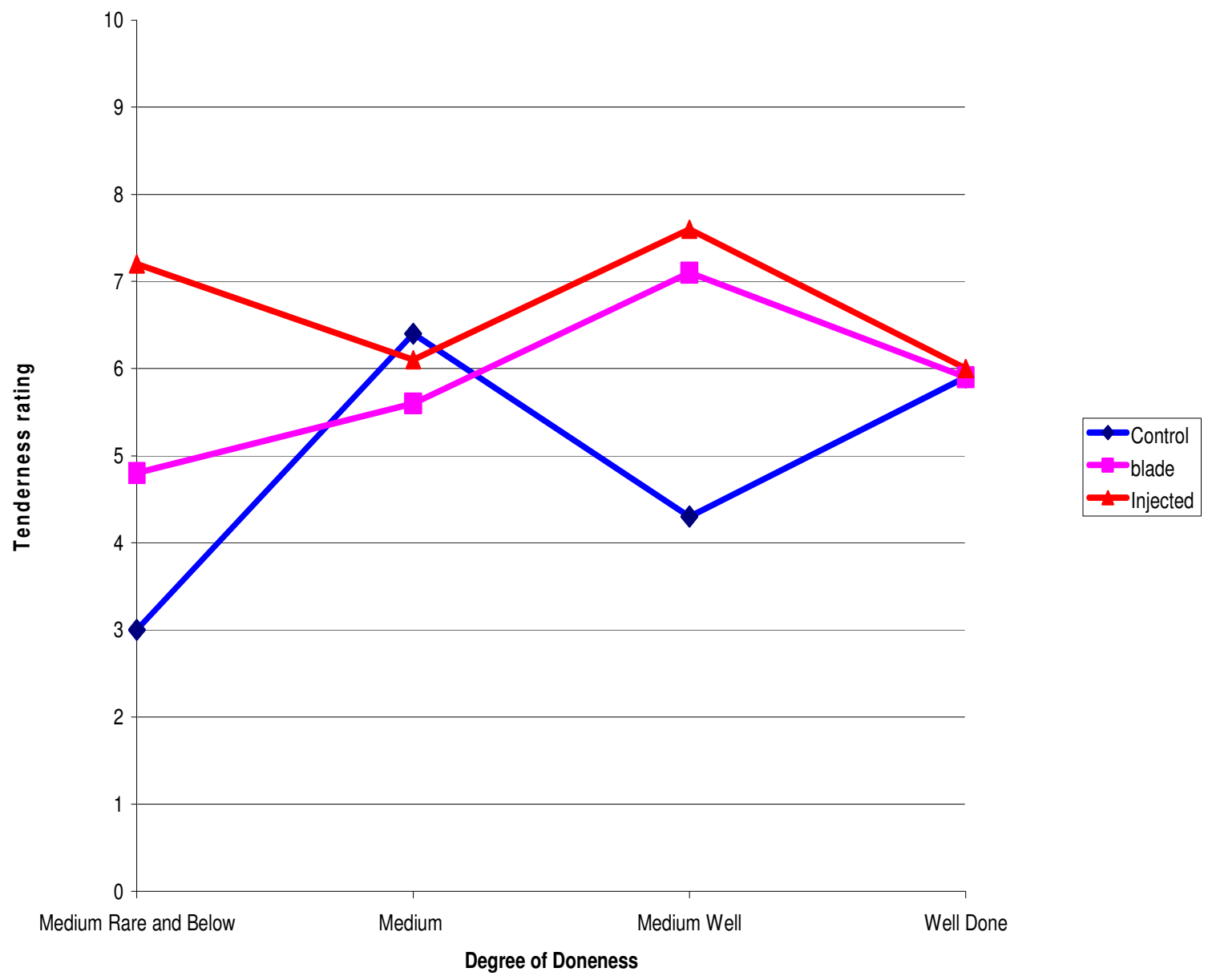

Figure 2. Interaction of Tenderization treatment and degree of doneness for tenderness ratings of the $M$. semimembranosus steaks cooked in a skillet. 


\section{CHAPTER IV}

\section{SUMMARY AND CONCLUSIONS}

Injecting round muscles with a salt and phosphate solution improved most palatability traits compared to those that were blade tenderized or were not treated. For the most part, cooking method and degree of doneness had little influence on consumer palatability ratings. Where differences occurred, they were muscle specific, which may allow limited recommendations for certain muscles with respect to the most appropriate cooking method and degree of doneness. 


\section{REFERENCES}

Belew, J. B., Brooks, J. C., McKenna, D. R., \& Savell, J. W. (2003). Warner-Bratzler shear evaluations of 40 bovine muscles. Meat Science, 64, 507-512.

Bloch, B. (1977). The meat board meat book. New York:

National Live Stock and Meat Board and the Benjamin Company, Inc.

Boleman, S. J., Boleman, S. L., Miller, R. K., Taylor, J. F., Cross, H. R., Wheeler, T. L., Koohmaraie, M., Shackelford, S. D., Miller, M. F., West, R. L., Johnson, D. D., \& Savell, J. W. (1997). Consumer evaluation of beef of known categories of tenderness. Journal of Animal Science, 75, 1521-1524.

Brooks, J. C., Belew, J. B., Griffin, D. B., Gwartney, B. L., Hale, D. S., Henning, W. R., Johnson, D. D., Morgan, J. B., Parrish, F. C., Jr., Reagan, J. O., \& Savell, J. W. (2000). National Beef Tenderness Survey - 1998. Journal of Animal Science, $78,1852-1860$.

Dikeman, M. E. (1987). Fat reduction in animals and the effects on palatability and consumer acceptance on meat products. In Proceedings of the $40^{\text {th }}$ reciprocal meat conference (pp. 93-103), 28 June- 1 July 1987, St Paul, MN.

Glover, E. E., Forrest, J. C., Johnson, H. R., Bramblett, V. D., \& Judge, M. D. (1977). Palatability and cooking characteristics of mechanically tenderized beef. Journal of Food Science, 42(4), 871-874.

Huffman, K. L., Miller, M. F., Hoover, S. C., Wu, C. K., Brittin, H. C., \& Ramsey, C. B. (1996). Effect of beef tenderness on consumer satisfaction with steaks consumed in the home and restaurant. Journal of Animal Science, 74, 91-97.

Jones, S. J., Burson, D. E., \& Calkins, C. R. (2001). Muscle profiling and bovine mycology-CD-Rom. Centennial, CO: National Cattlemen's Beef Association.

Kolle, B. K., McKenna, D. R., \& Savell, J. W. (2004). Methods to increase tenderness of individual muscles from beef rounds when cooked with dry or moist heat.

Meat Science, 68, 145-154.

Lorenzen, C. L., Miller, R. K., Taylor, J. F., Neely, T. R., Tatum, J. D., Wise, J. W., Buyck, M. J., Reagan, J. O., \& Savell, J. W. (2003). Beef customer satisfaction: Trained sensory panel ratings and Warner-Bratzler shear force values. Journal of Animal Science, 81, 143-149. 
Lorenzen, C. L, Neely, T. R., Miller, R. K., Tatum, J. D., Wise, J. W., Taylor, J. F., Buyck, M. J., Reagan, J. O., \& Savell, J. W. (1999). Beef customer satisfaction: Cooking method and degree of doneness effects on the top loin steaks. Journal of Animal Science, 77, 637-644.

Mandigo, R. W., \& Olson, D. G. (1982). Effect of blade size for mechanically tenderizing beef rounds. Journal of Food Science, 47, 2095-2096.

McGee, M. R., Henry, K. L., Brooks, J. C., Ray, F. K., \& Morgan, J. B. (2003). Injection of sodium chloride, sodium tripolyphosphate, and sodium lactate improves Warner-Bratzler shear and sensory characteristics of pre-cooked inside round roasts. Meat Science, 64, 273-277.

Miller, R. K. (1998). Functionality of non-meat ingredients used in enhanced pork. Des Moines, IA: National Pork Board. Available at: http://www.porkscience.org/documents/Other/functionalitynonmeat.pdf. Accessed March 10, 2005.

NAMP. (2003). The meat buyers guide. Reston, VA: North American Meat Processors Association.

Neely, T. R., Lorenzen, C. L., Miller, R. K., Tatum, J. D., Wise, J. W., Taylor, J. F., Buyck, M. J., Reagan, J. O., \& Savell, J. W. (1998). Beef customer satisfaction: Role of cut, USDA quality grade, and city on in-home consumer ratings. Journal of Animal Science, 76, 1027-1033.

Neely, T. R., Lorenzen, C. L., Miller, R. K., Tatum, J. D., Wise, J. W., Taylor, J. F., Buyck, M. J., Reagan, J. O., \& Savell, J. W. (1999). Beef customer satisfaction: Cooking method and degree of doneness effects on the top round steak. Journal of Animal Science, 77, 653-660.

Savell, J. W., Cross, H. R., Francis, J. J., Wise, J. W., Hale, D. S., Wilkes, D. L., \& Smith, G. C. (1989). National consumer retail beef study: Interaction of trim level, price and grade on consumer acceptance of beef steaks and roasts. Journal of Food Quality, 12, 251-274.

Savell, J. W., Lorenzen, C. L., Neely, T. R, Miller, R. K., Tatum, J. D., Wise, J. W., Taylor, J. F., Buyck, M. J., \& Reagan, J. O. (1999). Beef customer satisfaction: Cooking method and degree of doneness effects on the top sirloin steak. Journal of Animal Science, 77, 645-652.

Savell, J. W., Smith, G. C., \& Carpenter, Z. L. (1977). Blade tenderization of four muscles from the three weight-grade groups of beef. Journal of Food Science, $42,866-870,874$. 
Savell, J. W., \& Shackelford, S. D. (1992). The significance of tenderness to the meat industry. In Proceedings $45^{\text {th }}$ reciprocal meat conference (pp. 43-46), 14-17 June 1992, Fort Collins, CO.

USDA. (1996). Institutional meat purchase specifications for fresh beef products-PDF version. Washington, DC: USDA Agricultural Marketing Service. Available: http://www.ams.usda.gov/lsg/imps100.pdf. Accessed 06 November 2003. 


\title{
VITA
}

\author{
Name: $\quad$ Stacy Layne Mueller \\ Birthplace: New Braunfels, Texas \\ Hometown: New Braunfels, Texas \\ Education: Texas A\&M University \\ B.S., Agribusiness \\ May 2003 \\ Texas A\&M University \\ M.S., Animal Science (Meat Science) \\ December 2005 \\ Permanent 10085 FM 1863 \\ Address: $\quad$ New Braunfels, TX 78132
}

